\title{
The increase of snowfall in Northeast China after the mid-1980s
}

\author{
WANG HuiJun $^{1,2^{*}} \&$ HE ShengPing ${ }^{1,2,3}$ \\ ${ }^{1}$ Nansen-Zhu International Research Center, Institute of Atmospheric Physics, Chinese Academy of Sciences, Beijing 100029, China; \\ ${ }^{2}$ Climate Change Research Center, Chinese Academy of Sciences, Beijing 100029, China; \\ ${ }^{3}$ Graduate University of Chinese Academy of Sciences, Beijing 100049, China
}

Received July 1, 2012; accepted September 12, 2012; published online December 6, 2012

\begin{abstract}
We studied long-term variation of winter snowfall in Northeast China (NEC) for 1951-2010. Results show that NEC snowfall increased about 20\% during 1986-2010 relative to 1951-1985. Further investigation suggests that the snowfall increase is closely associated with weakening of the East Asian winter monsoon (EAWM). The physical processes were portrayed by this research. Weakening of EAWM led to weakened cold air flow from the north, thus resulted in the warming of the surface ocean along the Northeast Asia coast and more water vapor evaporated from the ocean surface to the atmosphere and further transported to NEC. Also, because of EAWM weakening, more water vapor from south, east and west of NEC was transported to NEC, increasing water vapor content and hence snowfall there. From an atmospheric circulation viewpoint, EAWM weakening strengthened convergence at low levels and divergence at high levels, thereby favoring increased vertical convection and snowfall.
\end{abstract}

winter snowfall, East Asian winter monsoon, interdecadal variability

Citation: $\quad$ Wang H J, He S P. The increase of snowfall in Northeast China after the mid 1980s. Chin Sci Bull, 2013, 58: 1350-1354, doi: 10.1007/s11434-012-5508-1

The East Asian winter monsoon (EAWM) is a vital system influencing Eastern China and Northeast China (NEC). Recent studies have revealed many observational facts. These include an EAWM weakening after the mid-1980s [1], more frequent heavy snowfall and resulting disasters [2-4], decline of autumn Arctic sea ice favoring more snowfall in the Northern Hemisphere [5], and a diminished interrelationship between the EAWM and El Niño-Southern Oscillation (ENSO) after the mid-1970s [1]. Therefore, studies on the EAWM and winter climate in East Asia should focus more on mid and high latitude processes in the atmosphere and cryosphere, rather than the ENSO [6-11].

The EAWM weakening after the mid-1980s is concurrent with warming of surface air, especially during nighttime in northern China and particularly in NEC [12]. Therefore, an important question is whether snowfall in NEC increased after the mid-1980s. If so, is the snowfall increase associated with EAWM weakening? What about the physical mechanism? We attempt to address these issues in this research.

*Corresponding author (email: wanghj@mail.iap.ac.cn)

\section{Data and method}

The datasets used include the National Centers for Environmental Prediction (NCEP) $2.5^{\circ} \times 2.5^{\circ}$ resolution reanalysis for 1951-2010 [13], sea surface temperature (SST) at $2.0^{\circ} \times 2.0^{\circ}$ resolution from the National Oceanic and Atmospheric Administration (NOAA) [14], the $1.0^{\circ} \times 1.0^{\circ}$ NOAA land precipitation reanalysis (http://www.esrl.noaa. gov/psd/data/gridded/data.precl.html), and the 160-station precipitation dataset of China. The East Asian winter monsoon index (EAWMI) is defined as the mean geopotential height at $500 \mathrm{hPa}$ in the area $\left(25^{\circ}-45^{\circ} \mathrm{N}, 110^{\circ}-145^{\circ} \mathrm{E}\right)$, for describing the East Asian trough closely associated with the EAWM and cold surge activity. The boreal winter climate is represented by the average December-January-February (DJF) climate.

\section{Results}

As indicated by Wang and He [1], the EAWM weakened 
during 1986-2012. Thus, we first analyzed the difference of winter precipitation between that period (P2) and 1951-1985 (P1). For most cases, precipitation fell as snow since temperature was below zero. For preciseness, we analyzed the data from both the 160-station precipitation data and the NOAA reanalysis, and plotted the differences in Figure 1. The two datasets are generally consistent, and
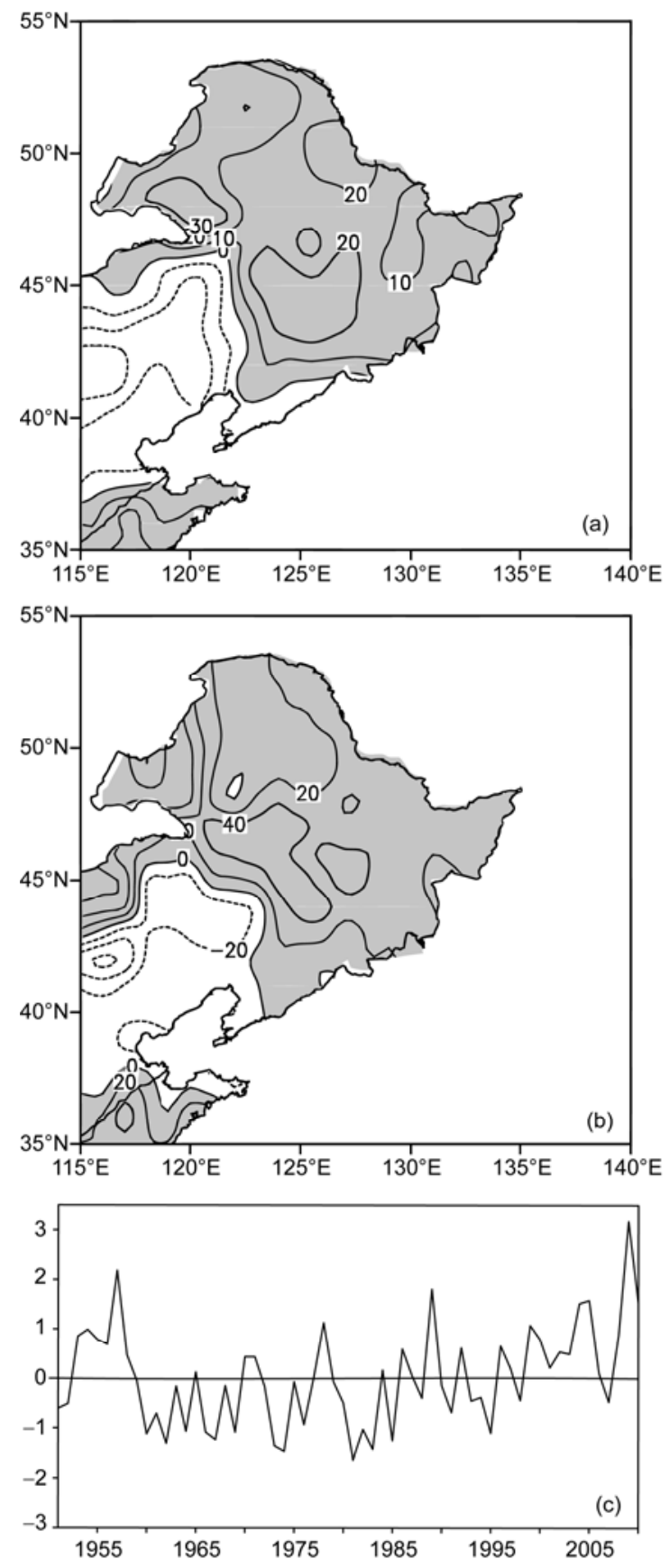

Figure 1 Difference between mean precipitation of 1986-2010 and 1951-1985, as indicated by percentile relative to average precipitation of 1961-1990 (a), and (b) based on NOAA reanalysis and station data in China. Shaded area indicates positive value. (c) Normalized time series of mean precipitation averaged within $\left(38^{\circ}-54^{\circ} \mathrm{N}, 115^{\circ}-135^{\circ} \mathrm{E}\right)$, based on the station dataset. show snowfall increased in P2 by about $20 \%$ over that of P1. The magnitude of the snowfall increase was larger in the western NEC than in the east.

Associated differences of winter velocity at $850 \mathrm{hPa}$ and surface air temperature are depicted in Figure 2. This clearly demonstrates the EAWM weakening. In addition, there is an anomalous cyclonic circulation near Lake Baikal. This is opposite the climatological anticyclonic circulation associated with the Siberian high pressure system and EAWM. This anomalous circulation pattern on the interdecadal scale is similar to that with interannual variability [15]. The weakened EAWM reduced cold air advection to NEC, warming the low-level atmosphere and surface. Therefore, we found that NEC surface air temperature was higher in P2 than P1.

The reduction of EAWM flow diminished the offshore cold northerly wind in the coastal region of the northeast Asia, warming the surface air (Figure 2(b)) and ocean surface (Figure 3) in P2 relative to P1. The out-of-phase relationship between the EAWM and sea surface temperature (SST) in that coastal region is shown by regression analysis of SST vs. the EAWM on the interannual scale (Figure 3(a)). Such EAWM-SST linkage is also found in both the detrended and non-detrended datasets. Therefore, the temperature increase of the surface air and ocean in the coastal region is physically associated with the EAWM weakening after the mid-1980s. The intensified Kuroshio Current may also play a role in the aforementioned coastal ocean warming.
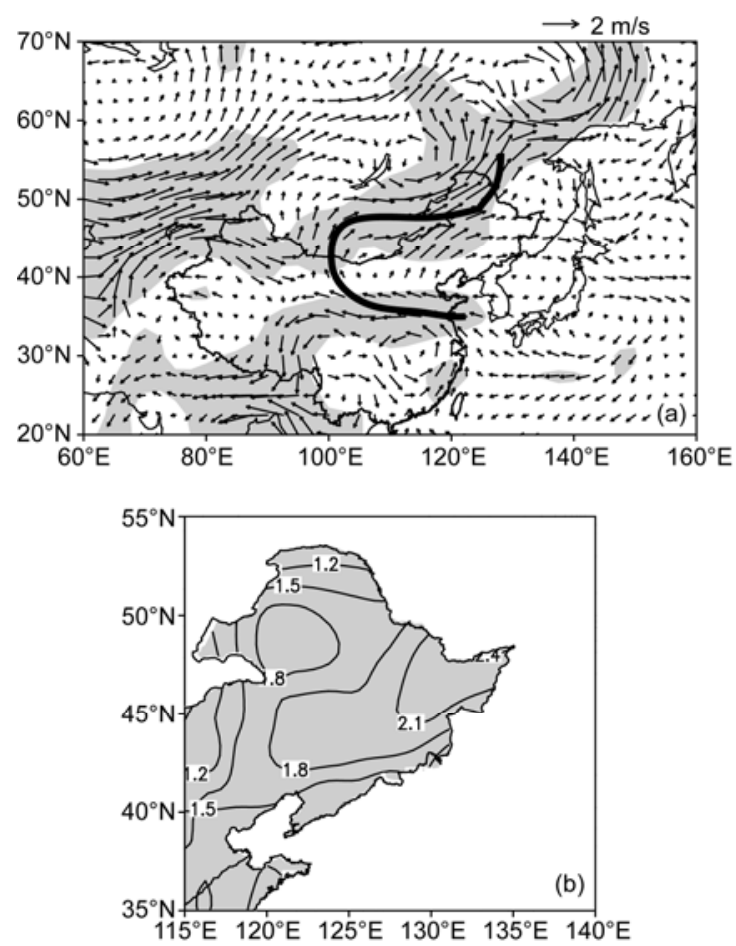

Figure 2 Difference of mean $850 \mathrm{hPa}$ velocity in $\mathrm{m} / \mathrm{s}$ (a), and surface air temperature in ${ }^{\circ} \mathrm{C}$ (b) between 1986-2010 and 1951-1985. In (a), shaded area indicates difference significant at $95 \%$ confidence level, and the black line indicates predominant winds. 

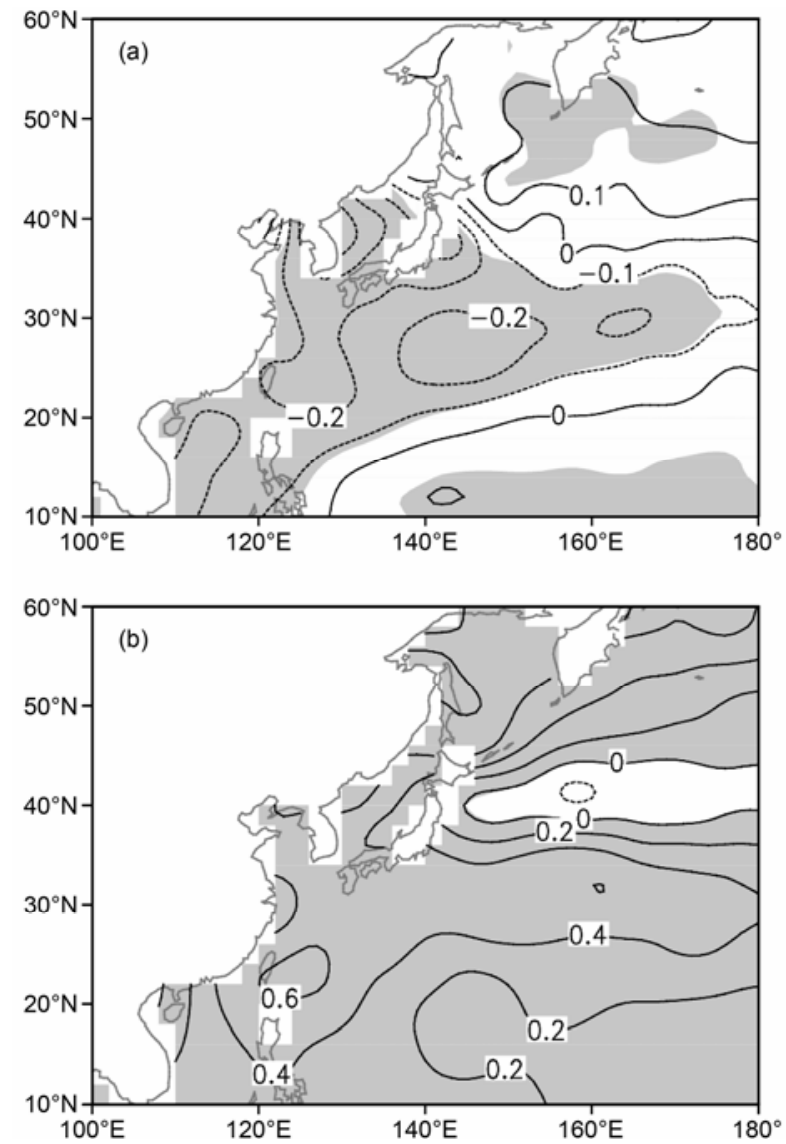

Figure 3 (a) Regressed SST vs. EAWM index during 1951-2010, with linear trend removed. Shaded area indicates regression significant at $95 \%$ confidence level. (b) Difference of mean SST in ${ }^{\circ} \mathrm{C}$ between 1986-2010 and 1951-1985.

Evaporation from the ocean surface increases because of the SST increase. The anomalous low-level velocity is southward or southeastward (Figure 2(a)), because of the EAWM weakening. Therefore, water vapor transport from the ocean and South China to NEC was enhanced in P2 over that of P1, as indicated by Figure 4. Moreover, the cyclonic anomalous circulation near Lake Baikal (Figure 2(a)) resulted in strengthened westerlies over the Mongolia region, which increased water vapor transport to NEC from the west. This is clearly depicted in Figure 4.

Therefore, water vapor transport from the west, south, and east all increased as a result of EAWM weakening. This would increase atmospheric water vapor content over NEC, as shown in Figure 5. This did increase throughout NEC by variable percentages, with a maximum increase of nearly $20 \%$ in northwestern NEC. Thus, the increase of the water vapor content over NEC favored the increased snowfalls in $\mathrm{P} 2$ relative to $\mathrm{P} 1$.

Increased snowfalls should be associated with more favorable dynamical conditions. To test this speculation, we plotted divergence differences between periods, at $850 \mathrm{hPa}$ and $100 \mathrm{hPa}$ (Figure 6). The results demonstrate that lowlevel $(850 \mathrm{hPa})$ convergence and high-level (100 hPa)

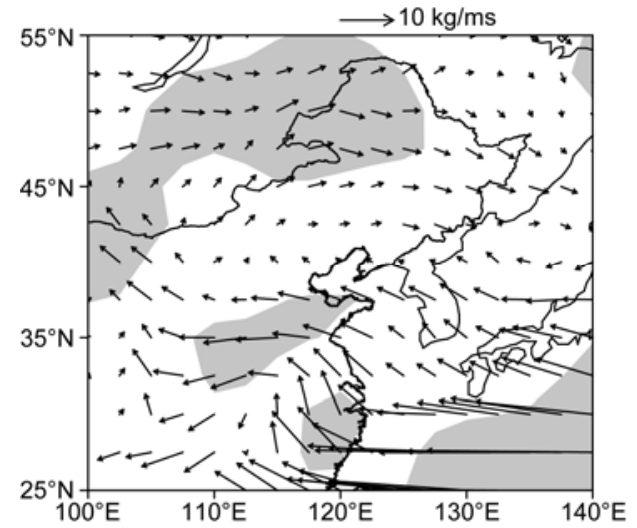

Figure 4 Difference of mean vertically integrated water vapor transport vector in $\mathrm{kg} / \mathrm{ms}$, between 1986-2010 and 1951-1985. Shaded area indicates difference significant at $95 \%$ confidence level.
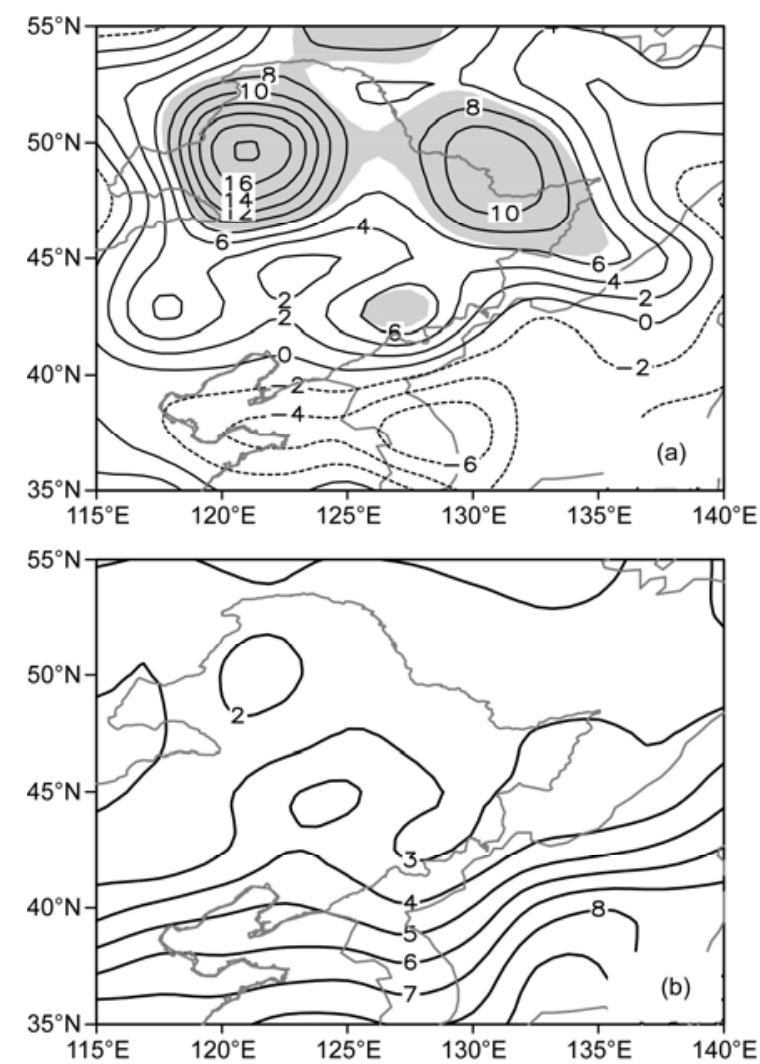

Figure 5 (a) Difference of mean atmospheric precipitable water content in \% between 1986-2010 and 1951-1985. Shaded area indicates difference significant at $95 \%$ confidence level. (b) Mean DJF atmospheric precipitable water content in $\mathrm{g} / \mathrm{kg}$.

divergence both intensified in P2 compared with P1, thereby strengthening vertical convection and providing favorable dynamical conditions for increased snowfalls.

There remain some issues regarding the snowfall increase after the mid-1980s, although there is robust evidence that EAWM weakening is at least partly responsible for the increased snowfall. First, is the EAWM weakening after the 

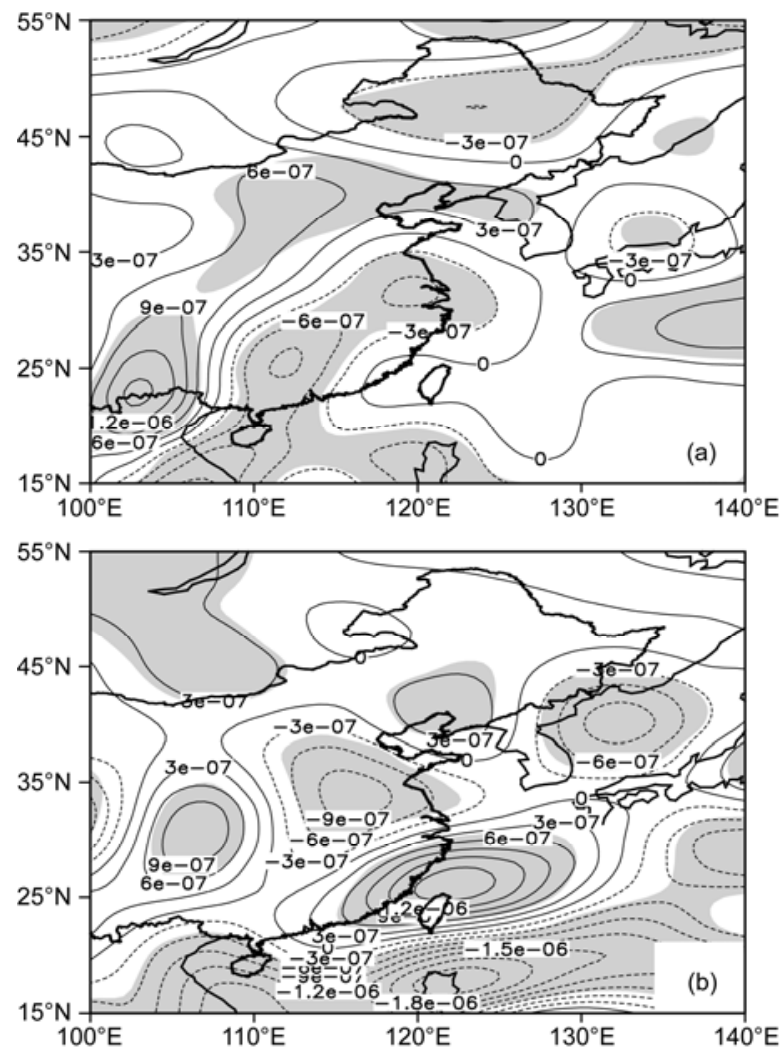

Figure 6 Differences of mean divergence $\left(\mathrm{s}^{-1}\right)$ between 1986-2010 and 1951-1985 at $850 \mathrm{hPa}(\mathrm{a})$, and $100 \mathrm{hPa}(\mathrm{b})$. Shaded area indicates difference significant at $95 \%$ confidence level.

mid-1980s attributable to natural variability of the coupled atmosphere-ocean-cryosphere-land surface, or to anthropogenic global warming via increased greenhouse gases in the atmosphere? This question remains largely uncertain. Although almost all climate model projections support the idea that anthropogenic warming can weaken the EAWM [12], natural climate variability may also regulate it to some extent. Second, a recent decline of autumn Arctic sea ice might have contributed to increased winter snowfall in Northern Hemisphere land areas [5]. However, we need further investigation on co-variability among the Arctic Oscillation, autumn Arctic sea ice, EAWM, and NEC snowfall. Third, the weakened EAWM resulted in the snowfall increase in NEC, but a decrease in central North China (Figure 1). Future studies should address how the weakened EAWM affects winter precipitation there, as well as in South China and the Korea-Japan region.

\section{Summary}

This paper documented increased winter snowfall in NEC after the mid-1980s, and explained associated physical processes. We showed that the weakened EAWM is at least partly responsible for the increased snowfall. This is ac- complished through decreasing northerly winds, increasing temperature in NEC and the coastal sea region, enhancing water vapor transport to NEC, reinforcing water vapor content there, intensifying low-level convergence and highlevel divergence, and strengthening convective activity over NEC. Nevertheless, there are some important issues to be addressed in future studies. There are diverse responses of winter precipitation to the weakened EAWM in East Asia, and the physical processes remain unclear. Recently, Zhang et al. [16] indicated a poleward retreat of the storm track in East Asia, which is closely associated with the EAWM weakening. Further, a warming ocean in recent decades supports continental surface air temperature changes [17]. These questions are worthy of further investigation. In addition, climate model-based studies with simulation and projection of winter snowfall and the EAWM are definitely necessary for understanding the physics involved. Related studies are also crucial for exploring techniques for climate predictions and projections [18-21].

This work was supported by the National Natural Science Foundation of China (41130103), National Basic Research Program of China (2009CB421406), and CAS-CSIRO Cooperative Research Program (GJHZ1223).

1 Wang H J, He S P. Weakening relationship between East Asian winter monsoon and ENSO after mid-1970s. Chin Sci Bull, 2012, 57: 3535-3540

2 Wang H J, Yu E T, Yang S. An exceptionally heavy snowfall in Northeast China: Large-scale circulation anomalies and hindcast of the NCAR WRF model. Meteorol Atmos Phys, 2011, 113: 11-25

3 Sun J Q, Wang H J, Yuan W. A preliminary investigation on causes of the catastrophic snowstorm in March, 2007 in the northeastern parts of China (in Chinese). Acta Meteorol Sin, 2009, 67: 469-477

4 Sun J Q, Wang H J, Yuan W, et al. Spatial-temporal features of intense snowfall events in China and their possible change. J Geophys Res, 2010, 115: D16110

5 Liu J P, Curry J A, Wang H J, et al. Impact of declining Arctic sea ice on winter snowfall. Proc Natl Acad Sci USA, 2012, doi: 10.1073/ pnas.1114910109

6 Zhang Y, Sperber K R, Boyle J S. Climatology and interannual variation of the East Asian winter monsoon: Results from the 1979-95 NCEP/NCAR reanalysis. Mon Weather Rev, 1997, 125: 2605-2619

7 Wang H J. The weakening of the Asian monsoon circulation after the end of 1970s. Adv Atmos Sci, 2001, 18: 376-386

8 Zhu C W, Lee W S, Kang H W, et al. A proper monsoon index for seasonal and interannual variations of the East Asian monsoon. Geophys Res Lett, 2005, 32: L02811

9 Gong D Y, Wang S W, Zhu J H. East Asian winter monsoon and Arctic Oscillation. Geophys Res Lett, 2001, 28: 2073-2076

10 Wang H J, Sun J Q. Variability of Northeast China river break-up date. Adv Atmos Sci, 2009, 26: 701-706

11 Wang L, Chen W, Huang R H. Interdecadal modulation of PDO on the impact of ENSO on the East Asian winter monsoon. Geophys Res Lett, 2008, L20702

12 Wang H J, Sun J Q, Chen H P, et al. Extreme climate in China: Facts, simulation and projection. Meteorol Zeitschrift, 2012, doi: 10.1127/ 0941-2948/2012/0330

13 Kalnay E, Kanamitsu M, Kistler R, et al. The NCEP/NCAR 40-year reanalysis project. Bull Am Meteorol Soc, 1996, 77: 437-471

14 Smith T M, Reynolds R W, Peterson T C, et al. Improvements to NOAA's historical merged land-ocean surface temperature analysis 
(1880-2006). J Clim, 2008, 21: 2283-2296

15 Zhao P, Zhang R H. Relationship of interannual variation between an Eastern Asia-Pacific dipole pattern and East Asian monsoon (in Chinese). Chin J Geophys, 2006, 30: 307-316

16 Zhang Y X, Ding Y H, Li Q P. Cyclone genesis frequency changes of extratropical cyclones in the northern hemisphere and east Asia revealed by ERA40 reanalysis data (in Chinese). Meteorol Monthly, 2012, 38: 646-656

17 Kaspi Y, Schneider T. Winter cold of eastern continental boundaries induced by warm ocean waters. Nature, 2011, 471: 621-624
18 Fan K. Predicting winter surface air temperature in Northeast China. Atmos Oceanic Sci Lett, 2009, 2: 14-17

19 Fan K. A statistical scheme for seasonal forecasting of North China winter temperature. Atmos Oceanic Sci Lett, 2011, 4: 81-85

20 Ma J H, Wang H J, Zhang Y. Will boreal winter precipitation over China increase in the future? An AGCM simulation under summer "ice-free Arctic" conditions. Chin Sci Bull, 2012, 57: 921-926

21 Wang H J, Zhang Y. Model projections of East Asian summer climate under the 'free Arctic' scenario. Atmos Oceanic Sci Lett, 2010, 3: $176-180$

Open Access This article is distributed under the terms of the Creative Commons Attribution License which permits any use, distribution, and reproduction in any medium, provided the original author(s) and source are credited. 